\title{
Analisis Perhitungan Rugi-Rugi Di Penyulang CDM Mochammad Toha - Bandung Hingga Trafo Distribusi
}

\author{
Muhammad Temmy $\mathbf{H}^{1}$, Nasrun Hariyanto ${ }^{2}$, Siti Saodah ${ }^{3}$ \\ 1,2,3 Institut Teknologi Nasional \\ 1,2,3 Jalan PH.H. Mustofa No.23 Bandung \\ temmyhilmansyah@gmail.com ${ }^{1}$,runhrt@gmail.com², ss_herlina@gmail.com
}

\begin{abstract}
Abstrak - Suatu sistem tenaga listrik pada umumnya terdiri dari beberapa unsur penting yaitu sistem pembangkitan, system transmisi, dan system distribusi. Oleh karena itu pentransmisian dan pendistribusian pun sangat berpengaruh terhadap kualitas listrik yang sampai ke konsumen, besarnya rugi-rugi listrik yang di hadapi PT.PLN (Persero) cukup besar sehingga harus di benahi karena sebagai faktor penting dalam pengembangan jaringan listrik ke depannya, cara perhitungan rugi-rugi daya dan energi listrik pada jaringan distribusi primer tegangan menengah, teknik tag GPS akan di lakukan simulasi jarak menggunakan aplikasi google earth, Simulasi aliran daya menggunakan aplikasi ETAP, maka dari hasil tersebut pun dapat digunakan sebagai acuan untuk perencanaan perluasan jaringan listrik di Indonesia, karena sangat berpengaruh terhadap nilai investasi jangka Panjang.
\end{abstract}

Kata Kunci: Rugi-rugi daya, susut energi, distribusi, transformator, simulasi

\section{Pendahuluan}

Sistem tenaga listrik secara keseluruhan terdiri dari pembangkitan, transmisi, dan distribusi. Sistem distribusi yang berfungsi menyalurkan dan mendistribusikan daya listrik dari pusat suplai ke kelompok beban harus mempunyai kualitas yang baik. Berdasarkan informasi yang diperoleh dari PT. PLN (Persero) Distibusi jawa barat, sebagian besar kerugian energy listrik terdapat pada jaringan distribusi, oleh karena itu rugi-rugi pada jaringan sangat perlu di perhatikan.

Untuk memperluas system jaringan distribusi, salah satu aspek yang perlu di perhatikan adalah efisiensi system distribusi yang baik, dengan tanpa mengabaikan aspek ekonomis. Efisiensi yang baik akan dicapai apabila rugi-rugi energy dapat ditekan sekecil mungkin. Dimana saat ini PT. PLN sedang terus memperluas jaringannya untuk meningkatkan kebutuhan beban yang setiap tahun nya terus meningkat, maka rugi-rugi yang terjadi pada jaringan distribusi harus menjadi pertimbangan untuk mengimbangi peningkatan dan perluasan jaringan, maupun pada perencanaan atau operasi, karena bias mempengaruhi biaya investasi dan pentarifan. Dengan diketahui besarnya rugi rugi daya, memungkinkan dilakukan oenelitian mengenai kemungkinan tambah investasi untuk mengurangi rugi-rugi tersebut.

Pada saat skarang ini perhitungan rugi-rugi energy pada system jaringan distribusi yang dilakukan PT. PLN adalah dengan mengurangi energy terjual dengan energy yang diterima pada setiap penyulang. Menginat pentingnya informasi mengenai besarnya rugi-rugi dari suatu jaringan distribusi yang dapat dipergunakan untuk penentuan tariff listrik dan rencana pengembangan jaringan, maka studi mengenai rugi-rugi energi pada system jaringan distribusi perlu dilakukan.

\section{Metoda Penelitian}

Perhitungan dilakukan pada masing-masing fasa untuk setiap gardu distribusi. Gambar 1 menunjukan tahapan perhitungan rugi daya beserta rumus yang digunakan.

TELKA, Vol.4, No.1, Mei 2018, pp. 24 32

ISSN (e): 2540-9123

ISSN (p): 2502-1982 


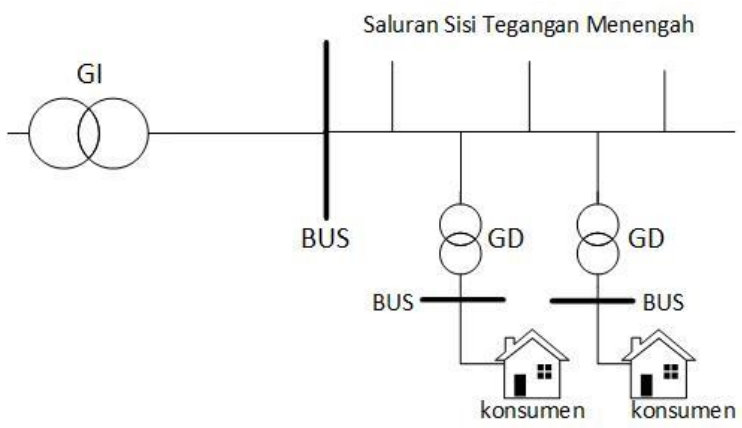

Gambar 1. Metodologi Perhitungan Rugi-rugi Daya

Kondisi ini menimbulkan batasan dalam melakukan perhitungan. Batas tersebut akan menentukan langkah-langkah perhitungan dan juga cara perhitungan parameter rugi-rugi daya. Batasan tersebut adalah:

1. Perhitungan hanya dilakukan pada bagian tegangan menengah saja hingga trafo distribusi saja.

2. Aplikasi yang digunakan untuk simulasi menggunakan Etap 12.6 dan pemetaan menggunakan google earth.

Perbandingan data hasil perhitungan dan hasil simulasi dilakukan agar dapat mengetahui seberapa besar selisih rugi-rugi daya yang terjadi dan seberapa akurat data yang dimiliki untuk di lakukan perhitungan, sehingga dapat di ketahui berapa jarak yang di dapatkan dengan teknik tag GPS, untuk emngatasi permasalahan yang sudah jelas , perhitungan di lakukan sesuai dengan Gambar 1. Metodologi tersebut menjelaskan tahapan dan cakupan daerah yang harus di lakukan perhitungan dan simulasi.

\subsection{Data beban sisi tegangan menengah}

Data beban pada sisi tegangan menegah ini didapatkan dari transformasi nilai beban pada sisi tegangan rendah terhadap perbandingan tegangan pengenal transformator.

$$
\begin{aligned}
& I_{T M}^{\prime}=\frac{V_{2}}{V_{1}} I_{T R} \text { (Ampere) } \\
& V_{T M}^{\prime}=\frac{V_{1}}{V_{2}} V_{T R}(\text { Volt }) \\
& S_{T M}{ }^{\prime}=V_{T M}{ }^{\prime} \times I_{T M}{ }^{\prime}(\mathrm{kVA})
\end{aligned}
$$

\subsection{Data transformator}

Untuk data kapasitas dan merk transformator didapat dari PLN, sedangkan data mengenai besarnya rugi besi dan rugi tembaga transformator didapatkan dari katalog dari merk transformator itu sendiri dan dari Standar PLN (SPLN) 50:1997. Rugi besi dan rugi tembaga transformator ini adalah rugi untuk transformator tiga fasa.

$\mathrm{K}_{\text {Transformator }}=$ Kapasitas transformator $(\mathrm{kVA})$

$\mathrm{P}_{\mathrm{Fe} 3 \text { fasa }} \quad=$ Rugi besi (Watt)

$\mathrm{P}_{\mathrm{Cu} 3 \text { Fasa }}=$ Rugi tembaga $($ Watt $)$

$$
\begin{aligned}
& \left(\mathrm{P}_{\mathrm{Fe} 1 \text { Fasa }}\right)=\frac{P_{F e} \text { f fasa }}{3}(\text { Watt }) \\
& \left(\mathrm{P}_{\mathrm{Cu} 1 \text { Fasa }}\right)=\frac{P_{\text {Cu } 3 \text { fasa }}}{3}(\text { Watt }) \\
& \left(\mathrm{I}_{\mathrm{n}}\right)=\frac{K_{\text {Transformator }}}{\sqrt{3 \cdot V_{1}}}(\text { Ampere }) \\
& \left(\mathrm{R}_{\mathrm{Cu}}\right)=\frac{P_{\text {Cu } 1 \text { Fasa }}}{\left(I_{n}\right)^{2}}(\Omega)
\end{aligned}
$$


2.3 Perhitungan rugi transformator pada saat pembebanan

Rugi transformator ini dihitung per fasa pada setiap gardu distribusi dan pada setiap pembebanan. Untuk rugi besi, besarnya nilai rugi ini bersifat konstan sedangkan untuk rugi tembaga nilainya tergantung dari besarnya beban (arus).

$$
\begin{aligned}
& \text { Rugi tembaga }=I_{T M}^{2} \cdot \mathrm{R}_{\mathrm{cu}}(\text { Watt }) \\
& \left(\mathrm{P}_{\text {Transformator }}\right)=\mathrm{P}_{\mathrm{fe} 1 \text { fasa }}+\mathrm{P}_{\mathrm{Cu} 1 \text { fasa }}(\text { Watt }) \\
& P_{\text {Transformator }} / \cos \varphi \\
& \left(\mathrm{S}_{\text {Transformator }}\right)=\frac{1000}{100}(\mathrm{kVA}) \\
& \% \text { Rugi Transformator }=\frac{S_{\text {Transformator }}}{S_{T M^{\prime}}} \times 100 \%
\end{aligned}
$$

\subsection{Daya pada sisi tegangan menengah}

$$
\mathrm{S}_{\mathrm{TM}}=\mathrm{S}_{\mathrm{TM}}{ }^{\prime}+\mathrm{S}_{\text {Transformator }}(\mathrm{kVa})
$$

\subsection{Arus pada sisi tegangan menengah}

$$
\mathrm{I}_{\mathrm{TM}}=\frac{S_{T M}}{V_{T M}}(\text { Ampere })
$$

\subsection{Perhitungan rugi saluran antara titik X-Y}

Rugi saluran ini, dihitung untuk setiap segmen yaitu antara titik yang satu dengan titik yang lainnya dan dihitung pada masing-masing fasa.

$$
\begin{aligned}
& \text { Rugi saluran }\left(\mathrm{P}_{\text {Saluran }}\right)=I_{T M}^{2} \cdot \mathrm{R} .1(\text { Watt }) \\
& \text { Rugi saluran }\left(\mathrm{S}_{\text {saluran }}\right)=\frac{P_{\text {Saluran }}}{\cos \varphi}(\mathrm{VA}) \\
& \% \text { Rugi Saluran }=\frac{S_{\text {Saluran }}}{S_{T M}} \times 100 \%
\end{aligned}
$$

\subsection{Rugi total antara titik X-Y}

Rugi total ini merupakan total dari rugi-rugi yang ada diantara titik X dan titik Y, yaitu rugi Transformator distribusi dan rugi saluran antara $\mathrm{X}$ dan $\mathrm{Y}$.

$$
\mathrm{P}_{\text {Total }}=\mathrm{P}_{\text {Transformator }}+\mathrm{P}_{\text {Saluran }}(\text { Watt })
$$

\subsection{Rugi-rugi total transformator}

Rugi-rugi transformator daya dapat dituliskan dengan persamaan berikut.

$$
\mathrm{P}_{\text {trafo }}=\mathrm{P}_{\mathrm{Fe}}+\mathrm{P}_{\mathrm{cu}}(\text { Watt })
$$

\section{Hasil Perhitungan Dan Analisis}

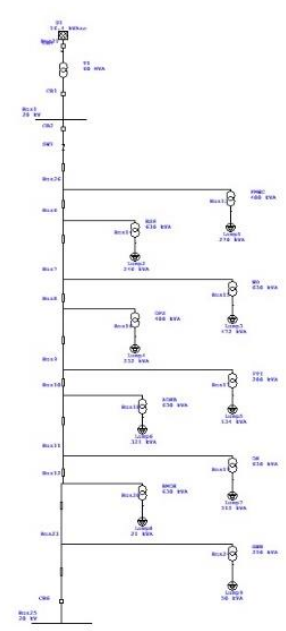

Gambar 2. Penyulang CDM 
Tabel 1. Rincian data perhitungan menggunkan data aktual

\begin{tabular}{cccccc}
\hline Waktu & $\begin{array}{c}\text { Beban } \\
\text { perhitungan } \\
\text { (KWatt) }\end{array}$ & $\begin{array}{c}\text { Rugi } \\
\text { Transformator } \\
\text { Perhitungan } \\
\text { (kWatt) }\end{array}$ & $\begin{array}{c}\text { Rugi Saluran } \\
\text { Perhitungan } \\
\text { (kWatt) }\end{array}$ & $\begin{array}{c}\text { Total } \\
\text { Rugi } \\
\text { (kWatt) }\end{array}$ & Rugi (\%) \\
\hline 1 & 2 & 3 & 4 & 5 & 6 \\
: 00 & 1555.6768 & 9.54127 & 0.48235 & 10.02362 & 0.644325 \\
$1: 00$ & 1532.664 & 9.541228 & 0.481613 & 10.02284 & 0.653949 \\
$2: 00$ & 1526.1328 & 9.540813 & 0.474692 & 10.01551 & 0.656267 \\
$3: 00$ & 1528.1928 & 9.540676 & 0.472412 & 10.01309 & 0.655224 \\
$4: 00$ & 1544.744 & 9.540951 & 0.477043 & 10.01799 & 0.648521 \\
$5: 00$ & 1501.3168 & 9.540539 & 0.470039 & 10.01058 & 0.666787 \\
$6: 00$ & 1533.2848 & 9.541089 & 0.479299 & 10.02039 & 0.653524 \\
$7: 00$ & 1531.5072 & 9.540813 & 0.474699 & 10.01551 & 0.653964 \\
$8: 00$ & 1511.6032 & 9.540539 & 0.47007 & 10.01061 & 0.662251 \\
$9: 00$ & 1517.5488 & 9.540951 & 0.476951 & 10.0179 & 0.660137 \\
$10: 00$ & 1523.972 & 9.541367 & 0.483887 & 10.02525 & 0.657837 \\
$11: 00$ & 1557.0232 & 9.541647 & 0.488637 & 10.03028 & 0.644196 \\
$12: 00$ & 1557.0232 & 9.541647 & 0.488637 & 10.03028 & 0.644196 \\
$13: 00$ & 1557.0232 & 9.541647 & 0.488637 & 10.03028 & 0.644196 \\
$14: 00$ & 1577.6856 & 9.541928 & 0.49337 & 10.0353 & 0.636077 \\
$15: 00$ & 1528.7984 & 9.541367 & 0.483882 & 10.02525 & 0.65576 \\
$16: 00$ & 1578.084 & 9.541787 & 0.491019 & 10.03281 & 0.635759 \\
$17: 00$ & 1578.1056 & 9.541507 & 0.486368 & 10.02787 & 0.635438 \\
$18: 00$ & 1621.1472 & 9.542211 & 0.498192 & 10.0404 & 0.619339 \\
$19: 00$ & 1629.0816 & 9.542354 & 0.500583 & 10.04294 & 0.616478 \\
$20: 00$ & 1587.5912 & 9.54183 & 0.491757 & 10.03359 & 0.632001 \\
$21: 00$ & 1548.832 & 9.541131 & 0.479997 & 10.02113 & 0.647012 \\
$22: 00$ & 1588.3576 & 9.541971 & 0.49406 & 10.03603 & 0.63185 \\
$23: 00$ & 1561.8416 & 9.54169 & 0.489321 & 10.03101 & 0.642255 \\
$0: 00$ & 1555.6768 & 9.54127 & 0.48235 & 10.02362 & 0.644325 \\
\hline & & & & &
\end{tabular}

Arus mengalir pada penghantar dengan resitansi yang menyebabkan terjadinya susut pada penghantar tersebut, sehingga daya yang dikirim dari gardu induk ke konsumen akan berkurang. (Kurt, 1990)

\subsection{Pengambilan Sampel Menggunakan Jarak Aktual}

Pengujian atau pengambilan sampel dilakukan selama 1 hari. Setiap jam dilakukan pengambilan sampel dari pukul 0:00 hingg pukul 24:00, pengujian dilakukan menggunakan aplikasi agar dapat di bandingkan dengan hasil perhitungan.

Tabel 2. Hasil dari simulasi Etap Menggunakan Data Aktual

\begin{tabular}{cccccc}
\hline WAKTU & $\begin{array}{c}\text { Beban } \\
\text { etap(Watt) }\end{array}$ & $\begin{array}{c}\text { Rugi } \\
\text { Transformator } \\
\text { etap (kWatt) }\end{array}$ & $\begin{array}{c}\text { Rugi } \\
\text { Saluran } \\
\text { etap(kWatt) }\end{array}$ & $\begin{array}{c}\text { Total } \\
\text { Rugi } \\
\text { (kWatt) }\end{array}$ & Rugi (\%) \\
\hline $0: 00$ & 1321 & 12.2 & 1.3 & 13.5 & 1.021953 \\
$1: 00$ & 1300 & 9 & 1.2 & 10.2 & 0.784615 \\
$2: 00$ & 1287 & 8.9 & 1.2 & 10.1 & 0.784771 \\
$3: 00$ & 1288 & 8.9 & 1.2 & 10.1 & 0.784161 \\
$4: 00$ & 1307 & 9 & 1.2 & 10.2 & 0.780413 \\
$5: 00$ & 1263 & 8.5 & 1.2 & 9.7 & 0.768013 \\
$6: 00$ & 1298 & 9 & 1.2 & 10.2 & 0.785824 \\
$7: 00$ & 1290 & 8.9 & 1.2 & 10.1 & 0.782946 \\
$8: 00$ & 1271 & 8.7 & 1.2 & 9.9 & 0.778914 \\
$9: 00$ & 1281 & 8.9 & 1.2 & 10.1 & 0.788447 \\
$10: 00$ & 1294 & 9 & 1.2 & 10.2 & 0.788253 \\
$11: 00$ & 1327 & 9.4 & 1.4 & 10.8 & 0.813866 \\
\hline
\end{tabular}

ISSN (e): 2540-9123

ISSN (p): 2502-1982 


\begin{tabular}{cccccc}
\hline WAKTU & $\begin{array}{c}\text { Beban } \\
\text { etap(Watt) }\end{array}$ & $\begin{array}{c}\text { Rugi } \\
\text { Transformator } \\
\text { etap (kWatt) }\end{array}$ & $\begin{array}{c}\text { Rugi } \\
\text { Saluran } \\
\text { etap(kWatt) }\end{array}$ & $\begin{array}{c}\text { Total } \\
\text { Rugi } \\
\text { (kWatt) }\end{array}$ & Rugi (\%) \\
\hline $12: 00$ & 1328 & 9.4 & 1.4 & 10.8 & 0.813253 \\
$13: 00$ & 1328 & 9.4 & 1.4 & 10.8 & 0.813253 \\
$14: 00$ & 1349 & 9.6 & 1.4 & 11 & 0.815419 \\
$15: 00$ & 1292 & 8.9 & 1.2 & 10.1 & 0.781734 \\
$16: 00$ & 1339 & 9.5 & 1.4 & 10.9 & 0.81404 \\
$17: 00$ & 1335 & 9.5 & 1.4 & 10.9 & 0.816479 \\
$18: 00$ & 1288 & 10.4 & 1.5 & 11.9 & 0.923913 \\
$19: 00$ & 1395 & 10.5 & 1.6 & 12.1 & 0.867384 \\
$20: 00$ & 1362 & 10 & 1.5 & 11.5 & 0.844347 \\
$21: 00$ & 1310 & 9.1 & 1.2 & 10.3 & 0.78626 \\
$22: 00$ & 1254 & 9.6 & 1.4 & 11 & 0.877193 \\
$23: 00$ & 1330 & 9.4 & 1.4 & 10.8 & 0.81203 \\
$0: 00$ & 1320 & 9.4 & 1.3 & 10.7 & 0.810606 \\
\hline & \multicolumn{5}{c}{}
\end{tabular}

\subsection{Pengambilan Sampel Menggunakan Jarak GPS}

Tabel 3. Rincian data perhitungan menggunkan data GPS

\begin{tabular}{cccccc}
\hline WAKTU & $\begin{array}{c}\text { Beban } \\
\text { perhitungan } \\
\text { (kWatt) }\end{array}$ & $\begin{array}{c}\text { Rugi } \\
\text { Transformator } \\
\text { Perhitungan } \\
\text { (kWatt) }\end{array}$ & $\begin{array}{c}\text { Rugi Saluran } \\
\text { Perhitungan } \\
\text { (kWatt) }\end{array}$ & $\begin{array}{c}\text { Total } \\
\text { Rugi } \\
\text { (kWatt) }\end{array}$ & Rugi (\%) \\
\hline $0: 00$ & 1555.6768 & 9.54127 & 1.026752 & 10.56802 & 0.67932 \\
$1: 00$ & 1532.664 & 9.541228 & 1.025215 & 10.56644 & 0.689417 \\
$2: 00$ & 1526.1328 & 9.540813 & 1.010825 & 10.55164 & 0.691397 \\
$3: 00$ & 1528.1928 & 9.540676 & 1.006081 & 10.54676 & 0.690146 \\
$4: 00$ & 1544.744 & 9.540951 & 1.015715 & 10.55667 & 0.683393 \\
$5: 00$ & 1501.3168 & 9.540539 & 1.001149 & 10.54169 & 0.702163 \\
$6: 00$ & 1533.2848 & 9.541089 & 1.020407 & 10.5615 & 0.688815 \\
$7: 00$ & 1531.5072 & 9.540813 & 1.010842 & 10.55166 & 0.688972 \\
$8: 00$ & 1511.6032 & 9.540539 & 1.00121 & 10.54175 & 0.697389 \\
$9: 00$ & 1517.5488 & 9.540951 & 1.015519 & 10.55647 & 0.695626 \\
$10: 00$ & 1523.972 & 9.541367 & 1.029938 & 10.57131 & 0.693668 \\
$11: 00$ & 1557.0232 & 9.541647 & 1.039809 & 10.58146 & 0.679595 \\
$12: 00$ & 1557.0232 & 9.541647 & 1.039809 & 10.58146 & 0.679595 \\
$13: 00$ & 1557.0232 & 9.541647 & 1.039809 & 10.58146 & 0.679595 \\
$14: 00$ & 1577.6856 & 9.541928 & 1.049638 & 10.59157 & 0.671336 \\
$15: 00$ & 1528.7984 & 9.541367 & 1.029925 & 10.57129 & 0.691477 \\
$16: 00$ & 1578.084 & 9.541787 & 1.044763 & 10.58655 & 0.670848 \\
$17: 00$ & 1578.1056 & 9.541507 & 1.035099 & 10.57661 & 0.670209 \\
$18: 00$ & 1621.1472 & 9.542211 & 1.059632 & 10.60184 & 0.653972 \\
$19: 00$ & 1629.0816 & 9.542354 & 1.064638 & 10.60699 & 0.651103 \\
$20: 00$ & 1587.5912 & 9.54183 & 1.046304 & 10.58813 & 0.666931 \\
$21: 00$ & 1548.832 & 9.541131 & 1.021866 & 10.563 & 0.681998 \\
$22: 00$ & 1588.3576 & 9.541971 & 1.051094 & 10.59306 & 0.666919 \\
$23: 00$ & 1561.8416 & 9.54169 & 1.041243 & 10.58293 & 0.677593 \\
$0: 00$ & 1555.6768 & 9.54127 & 1.026752 & 10.56802 & 0.67932 \\
\hline & & & & & \\
\hline
\end{tabular}


Tabel 4. Hasil dari simulasi Etap Menggunakan Data Aktual

\begin{tabular}{|c|c|c|c|c|c|}
\hline WAKTU & $\begin{array}{c}\text { Beban } \\
\text { etap }(k W a t t)\end{array}$ & $\begin{array}{c}\text { Rugi } \\
\text { Transformator } \\
\text { etap (kWatt) }\end{array}$ & $\begin{array}{c}\text { Rugi } \\
\text { Saluran } \\
\text { etap(kWatt) }\end{array}$ & $\begin{array}{c}\text { Total } \\
\text { Rugi } \\
\text { (kWatt) }\end{array}$ & Rugi (\%) \\
\hline 0:00 & 1320 & 9.4 & 2.5 & 11.9 & 0.901515 \\
\hline $1: 00$ & 1302 & 9 & 2.4 & 11.4 & 0.875576 \\
\hline $2: 00$ & 1287 & 8.9 & 2.4 & 11.3 & 0.878011 \\
\hline $3: 00$ & 1289 & 8.9 & 2.4 & 11.3 & 0.876649 \\
\hline 4:00 & 1305 & 9.1 & 2.4 & 11.5 & 0.881226 \\
\hline 5:00 & 1262 & 8.5 & 2.3 & 10.8 & 0.855784 \\
\hline $6: 00$ & 1297 & 9 & 2.4 & 11.4 & 0.878951 \\
\hline $7: 00$ & 1290 & 8.9 & 2.4 & 11.3 & 0.875969 \\
\hline 8:00 & 1272 & 8.8 & 2.3 & 11.1 & 0.872642 \\
\hline 9:00 & 1281 & 8.9 & 2.4 & 11.3 & 0.882123 \\
\hline $10: 00$ & 1294 & 9 & 2.4 & 11.4 & 0.880989 \\
\hline 11:00 & 1327 & 9.4 & 2.5 & 11.9 & 0.89676 \\
\hline $12: 00$ & 1327 & 9.4 & 2.5 & 11.9 & 0.89676 \\
\hline $13: 00$ & 1327 & 9.4 & 2.5 & 11.9 & 0.89676 \\
\hline $14: 00$ & 1348 & 9.6 & 2.6 & 12.2 & 0.905045 \\
\hline $15: 00$ & 1291 & 9 & 2.4 & 11.4 & 0.883036 \\
\hline $16: 00$ & 1337 & 9.5 & 2.6 & 12.1 & 0.905011 \\
\hline $17: 00$ & 1335 & 9.5 & 2.6 & 12.1 & 0.906367 \\
\hline $18: 00$ & 1390 & 10.4 & 2.9 & 13.3 & 0.956835 \\
\hline $19: 00$ & 1394 & 10.4 & 2.9 & 13.3 & 0.954089 \\
\hline 20:00 & 1362 & 10 & 2.9 & 12.9 & 0.947137 \\
\hline 21:00 & 1309 & 9.1 & 2.4 & 11.5 & 0.878533 \\
\hline $22: 00$ & 1352 & 9.6 & 2.7 & 12.3 & 0.909763 \\
\hline $23: 00$ & 1329 & 9.4 & 2.5 & 11.9 & 0.89541 \\
\hline 0:00 & 1320 & 9.4 & 2.5 & 11.9 & 0.901515 \\
\hline
\end{tabular}

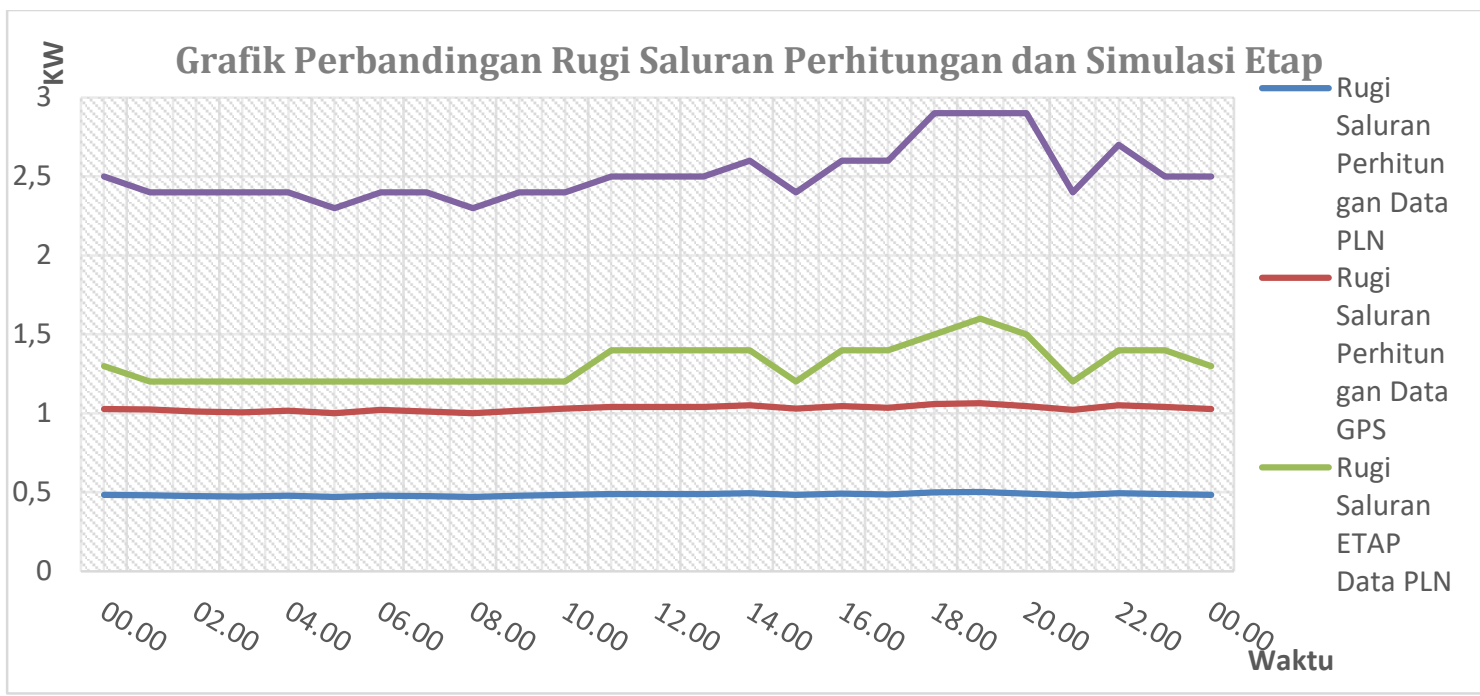

Gambar 3. Grafik Perbandingan Penelitian

Dengan adanya gambar 3. Dapat di lihat perbedaan pada setiap percobaan di mana data aktual paling rendah nilai rugi saluranya sedangkan rugi saluran menggunakan data GPS paling besar rugi saluranya, hal tersebut dapat terjadi karena selisih jarak yang terjadi pada data aktual dan GPS sehingga mempengaruhi impedansi salurannya. 


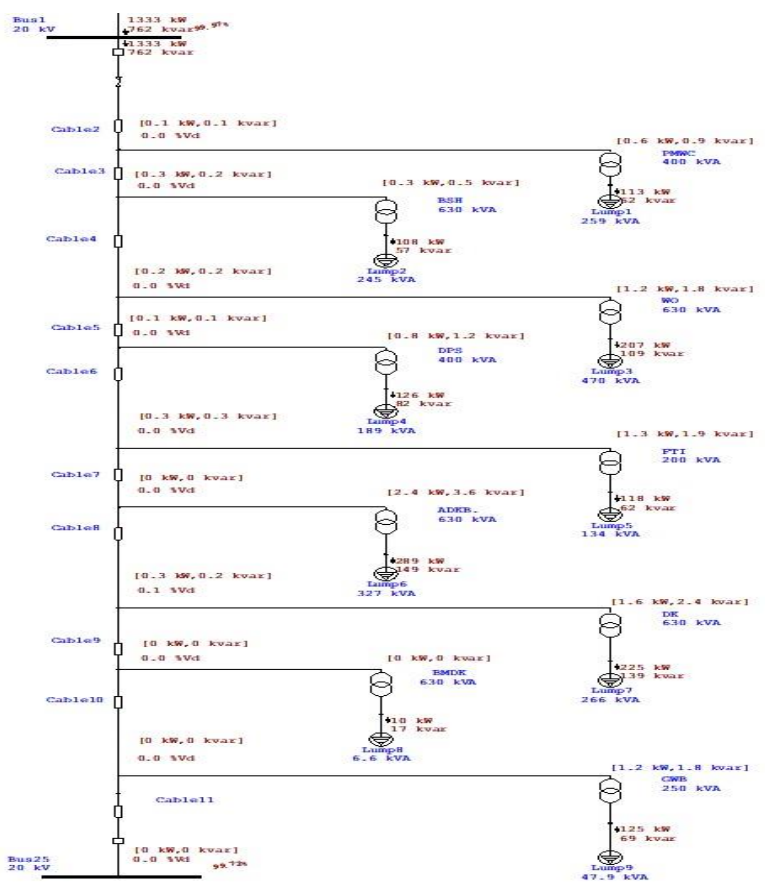

Gambar 4. Simulasi Etap menggunakan jarak PLN Pukul 0:00

Dengan melihat hasil simulasi etap bisa terlihat seberapa besar dan berapa nilai-nilai yang terjadi pada suatu penyulang di mana simulasi di lakukan dengan dua data berbeda yaitu data jarak dari PT.PLN (Persero) dan data jarak tag GPS , dengan melihat besar nilai kabel 2 pada gambar 4.6 sebesar 0,1 KWdan kabel 2 pada gambar 4.7 sebesar $0,9 \mathrm{KW}$, hal tersebut bisa terjadi karena ada perbedan jarak penghantar antara data aktual dan GPS, karena semakin panjang suatu saluran semakin besar juga hambatanya.

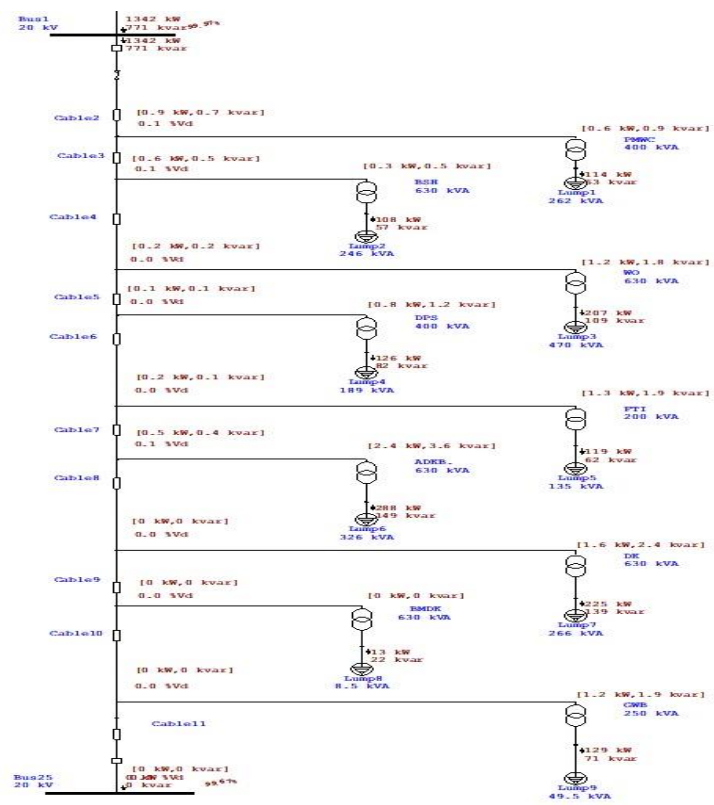

Gambar 5. Simulasi Etap menggunakan data jarak GPS pukul 0:00

Nilai-nilai yang terjadi pada simulasi Etap menggunakan data GPS memiliki nilai rugi-rugi daya saluran yang lebih besar di bandingkan dengan simulasi pada gambar 4.6, nilai ini di pengaruhi oleh panajng saluranya karena pada data GPS panjang saluran menjadi lebih panjang karena memang terjadi selisih jarak. 


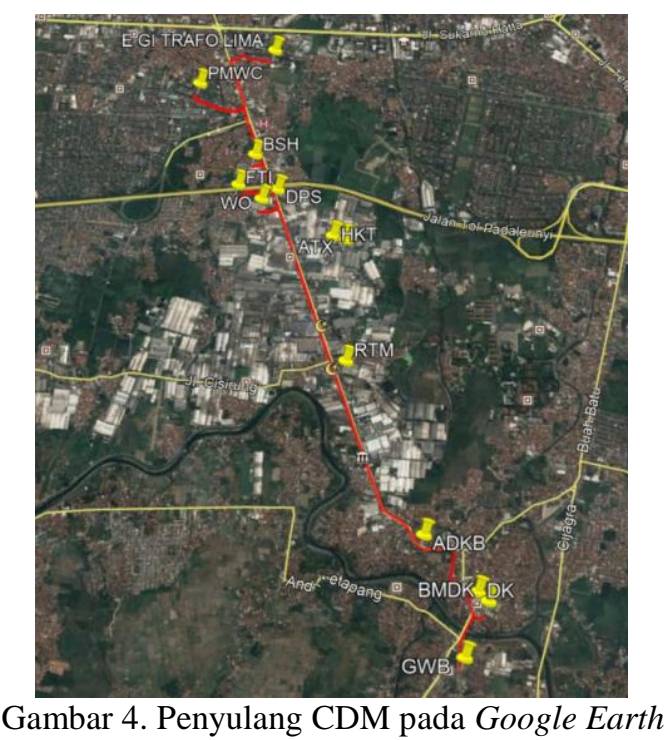

Bisa kita lihat hasil dari pemetaan yang dilakukan dengan aplikasi google earth bahwa penyulang CDM memiliki saluran yang jarak antara trafonya tidak seimbang, maksud nya tidak seimbang adalah ada salah satu jarak antara trafo yang lebih jauh d bandingkan jarak trafo lainya. Dan disini saya juga memasukan beberapa gambar dari trafo distribusi penyulang lain, yaitu ATX, HKT, RTM

\section{Kesimpulan}

Dari hasil perhitungan yang di lakukan didapatkan rugi daya penyulang selama 1 hari adalah sebesar $250.6340912 \mathrm{KW}$. Sedangkan dari hasil perhitungan memakai aplikasi Google Earth untuk kasus penyulang dengan kondisi beban yang sama didapatkan hasil sebesar 264.2882627 kW. Dengan demikian selisis antara perhitungan dengan hasil tag GPS yang di lakukan adalah sebesar $5.1 \%$.

Besar rugi saluran untuk Etap dengan data dari PLN sebesar 32,8 KW dan untuk simulasi Etap menggunakan jarak tag GPS sebesar 62,8 KW selisih tersebut di karenakan pengukuran jarak PLN masih menggunakan data base saat perencanaan pembuatan saluran transmisi, dan sudah lama tidak di lakukan pengukuran jarak ulang.

Setelah dilakukan pemetaan saja kita bisa langsung melihat masalah yang terjadi dan solusinya , karena masalah yang kita lihat di penyulang CDM adalah jarak yang tidak seimbang, namun setelah kita lihat pemetaan trafo lain di tengah jarak trafo FTI - ADKB ada posisi trafo penyulang lain yang di dapat kita gunakan sebagai tambahan bagi penyulang CDM.

Banyak hal yang dapat mempengaruhi terjadinya selisih data jarak, diantaranya posisi tag yang kurang tepat meskipun akurasi GPS baik.

\section{Daftar Pustaka}

[1] Zuhal, Dasar Teknik Tenaga Listrik dan Elektronika Daya, Gramedia. Jakarta, (2000).

[2] Standar PLN 50, Spesifikasi Transformator Distribusi, (1997).

[3] Aulia Nur F, Analisis Perhitungan Susut Daya dan Energi Pada Penyulang X di Sisi Tegangan Menengah sampai Trafo Distribusi, Institut Teknologi Nasional. Bandung, (2017).

[4] Akbar, A. Ali, Perhitungan Susut Daya Pada Sistem Distribusi Saluran Udara (SUTM) Penyulang CWRA GIS Kiara Condong dan Saluran Kabel (SKTM) Penyulang CBB GI Cigereleng. Bandung.(2006). 
[5] Ramadhianto, Danang, Studi Susut Energi Pada Sistem Distribusi Tenaga Listrik Melalui Analisis Pengukuran dan Perhitungan, Skripsi, Universitas Indonesia, (2008).

[6] Wasi, M. Riyan, Perhitungan Rugi-rugi Daya dan Energi pada SKTM 20kV di GI Cigereleng - GH Braga dengan Metoda Gauss Seidel. Bandung, (2007).

[7] Mukundufite Fabien, Reduction of Power Loss in Transmission and Distribution Lines by Respect of Comprehensive Planning in Combination with DG Installations Close to Consumers in Rwanda. University of Rwanda, Butare, Rwanda (2016). 